\title{
Ein Blick zurück: 70 Jahre «Salon des Médecins Suisses»
}

\section{Bernhard Weidmann, Präsident}

Dr. med., Präsident der Kunstausstellung der Schweizer Ärzte

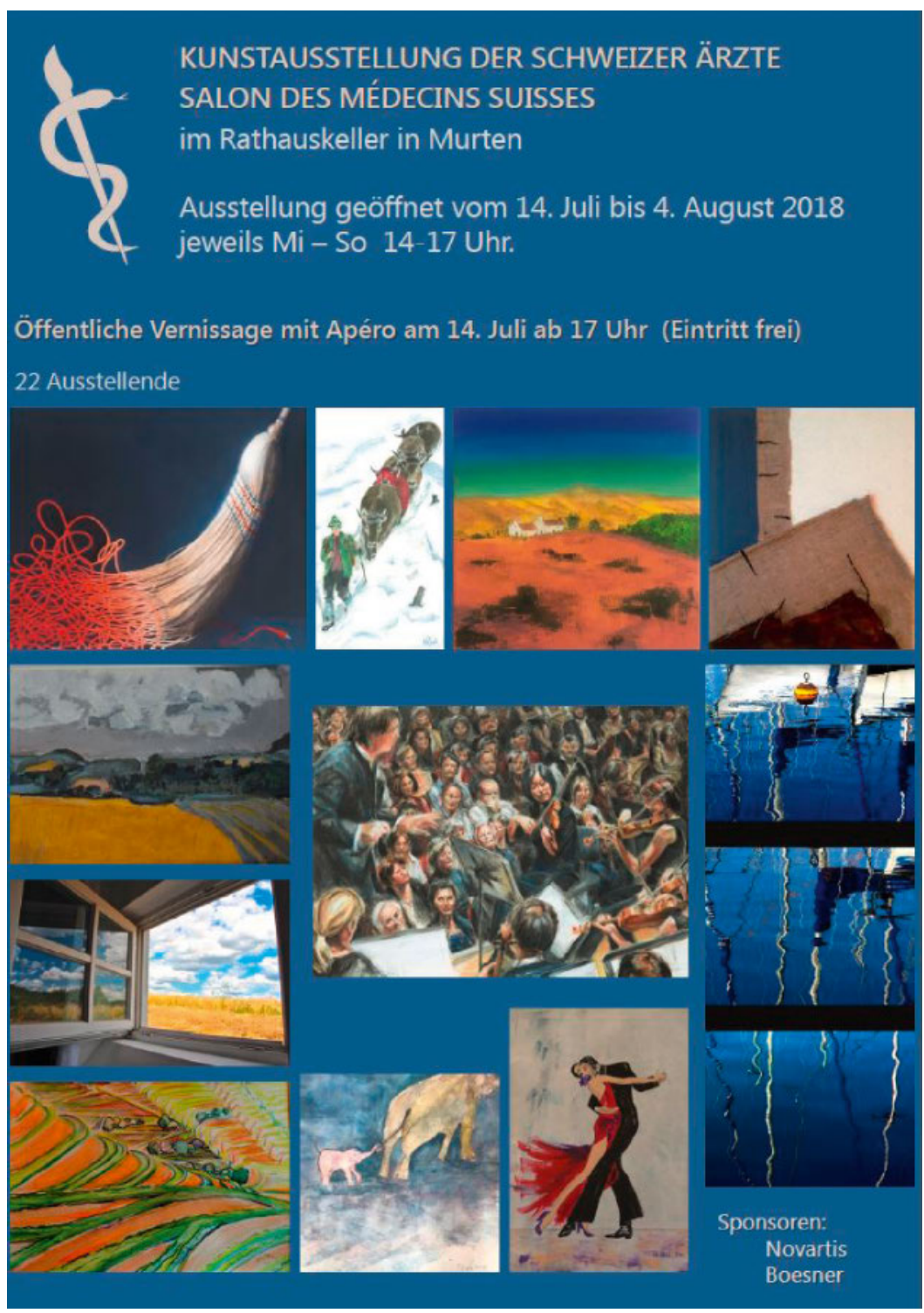

Einladung zur Kunstausstellung 2018

Die diesjährige Kunstausstellung der Schweizer Ärzte/Salon des Médecins Suisses findet vom 15.7.-4.8.2018 im Rathaussaal im Zentrum von Murten statt.

Öffnungszeiten: Mi-So von 14 bis 17 Uhr (auch am 1.8.2018). Der Eintritt ist frei. Die Vernissage mit Apéro vom 14.7.2018 ist öffentlich und beginnt um 17 Uhr.

Haben wir Ihr Interesse geweckt? Falls Sie mehr über uns wissen möchten, dann besuchen Sie unsere Website www.aerzte-kunst.ch.

\section{In Paris fing alles an}

Ärzte waren seit eh und je kreativ, sei es musikalisch, schriftstellerisch oder eben im Bereiche der bildenden Kunst. So fügten sich neben den professionellen Künstlern Ärzte zu Vereinigungen oder Vereinen zusammen. In Paris, dem Kunstzentrum zu Beginn des 20. Jahrhunderts, entstand 1909 (vermutlich) der erste solche Verein Europas. Ausgestellt wurde alle zwei Jahre. Von der zweiten Ausstellung, welche im Jahr 1911 in der Salle Berlitz am Boulevard des Italiens 31 stattfand, zeugt noch ein Werbeplakat, welches eine Szene festhält, wie ein Arzt während der Freizeit in ländlicher Gegend, den Kittel ausgezogen auf einem Baumstamm sitzend und den Zylinderhut neben sich im Gras liegend, eine Landschaft mit zwei alten Leuten skizziert (Holzschnitt von Paul-Emile Colin, 1867-1949).

1935 bildete sich ein solcher Verein in England, 1946 der "Cercle Art et Médecine» in Belgien, 1949 in den Niederlanden der Verein "pincet en penseel» (Pinzette und Pinsel). Von Italien ist 1951 eine Vereinigung «Associazione medici e sanitari artistici» mit Sitz in Modena bekannt, in Österreich gab es bei der Ärztekammer Wien die «Gesellschaft für Kunst und Medizin» und in Deutschland Kunstausstellungen von malenden Ärzten in Sulzbach-Saar und in München.

\section{Gründung des «Salon des Médecins Suisses»}

1947 ergriff Dr. med. François Forel, Landarzt in Chigny bei Morges VD, die Initiative zur Vereinsbildung des «Salon des Médecins Suisses». 1948 kam es zur Gründungsversammlung unseres Vereins in Lausanne. Er feiert dieses Jahr seinen 70. Geburtstag! Aus dem heute noch einsehbaren Protokollbuch ist zu entnehmen, dass der Verein zu Beginn gleich 42 Mitglieder zählte. Er bestand aus 40 Ärzten und 2 Ärztinnen, 25 Mitglieder stammten aus der Deutschschweiz, 16 Mitglieder aus der französischen und ein Mitglied aus der italienischen Schweiz. An der Versammlung in Lausanne waren 19 Mitglieder zugegen. Prof. Werner Hadorn (selber Aquarellist), Bern, wurde zum ersten Vorsit- 
zenden ernannt, Dr. Babisser, Lausanne, zum Sekretär und Dr. François Forel, der eigentliche Initiant des Vereins, zum Kassier. Der Jahresmitgliedsbeitrag betrug

\section{8 kam es zur Gründungsversammlung unseres Vereins in Lausanne.}

10 CHF. Es wurden vorerst keine Statuten aufgestellt, denn man war sich einig, dass «es der Lebensweise von Künstlern widerspreche», solches an die Hand zu nehmen.

\section{Seit 1948 jährliche Kunstausstellungen}

Ein Jahr später folgten die Generalversammlungen und jährliche Ausstellungen:

- 1949, Restaurant Innere Enge, Bern (damals Prägung des deutschen Vereinsnamens «Kunstausstellung der Schweizer Ärzte»)

- 1950, Galerie Chichio Haller, Zürich

- 1952, Palais de l'Athénée, Genf

- 1953, Kunsthalle Basel

- 1954, Hotel Carlton-Tivoli in Luzern

- 1955 am Ärztetag in Bern

- 1956 in der Berufsschule Solothurn (Genehmigung erste Statuten!)

- 1957 im Kurbrunnen Rheinfelden

- 1958 in der Universität Freiburg

- 1959 im Salinenhotel in Rheinfelden

- 1960 am Schweizerischen Ärztetag in Zürich

- 1961 in Locarno

- 1962, Kunsthaus Glarus

- 1963 in Stampa, Bergell

- 1964, Chalet Sauvabelin, Lausanne

- 1965 in der Abtei Bellelay usw.

Übers Jahr organisierten und genossen die Mitglieder auch Führungen im kleinen Rahmen mit Besuchen von Museen und Ausstellungen (z.B. Kunstmuseum Colmar, Besichtigung Schloss Thunstetten), oder sie liessen sich durch private Beziehungen auch Privatsammlungen wie Schmid-Müller in Beromünster, Rupf in Bern oder Baron Robert von Hirsch in Basel zeigen.

In den Anfangsjahren des Vereins wurde eine externe Jury aus Kunstexperten nominiert, welche die Kunst- werke beurteilen und zur Jahresausstellung oder gar für den Versand an eine internationale Ausstellung malender Ärzte (Paris 1950 und Turin 1951) auswählen sollte. Bei Abweisungen von Werken kam es dann oft zu Streitigkeiten, weshalb man 1961 die Einrichtung einer externen Jury aus den Statuten für immer verbannte.

\section{Wer durfte und darf Mitglied werden?}

Als Mitglieder zugelassen waren von Anfang an Ärztinnen und Ärzte mit Wohnsitz in der Schweiz. Schon bei der zweiten Sitzung (1949) kam die Diskussion auf, ob Medizinalpersonen wie Zahnärzte, Apotheker und Tierärzte auch Mitglieder werden dürften. Man entschied sich, diese nur als Gast aufzunehmen. Später kam es einmal zu einer Ausstellung inklusive Kinderzeichnungen von Nachkommen der Mitglieder. Unsere Aktivmitglieder sind heute vorwiegend Ärzte, aber

\section{Unsere Aktivmitglieder sind heute vorwiegend} Ärzte.

auch PartnerInnen von Mitgliedern, Studierende der Medizin und Angestellte in verwandten Berufen, welche der Medizin verwandt sind. Wir haben drei Auslandmitglieder.

\section{Murten - seit den 90er Jahren Ausstellungsort}

Seit 1990 finden die Generalversammlungen und die Jahresausstellungen regelmässig in den Monaten Juli und August in Murten statt. Rund zwanzig bis dreissig der fünfzig Aktivmitglieder zeigen gut hundert Werke von beachtlichem Niveau (Bilder in verschiedenen Techniken wie Öl-, Acryl- und Aquarellmalerei, Zeichnungen, Collagen, Drucke, Fotografien oder Plastiken aus verschiedenen Materialien und Keramik). Als Ausstellungslokalität dient der gediegene, direkt von der Gasse zugängliche Rathaussaal im Zentrum von Murten. Neben den Murten Classics (klassische Musik im Schlosshof) gehört unsere Jahresausstellung mittlerweile zu den etablierten Anlässen im mittelalterlichen Städtchen. 